\title{
Study of Precursors Responsible for Off-Flavor Formation during Storage of Potato Flakes
}

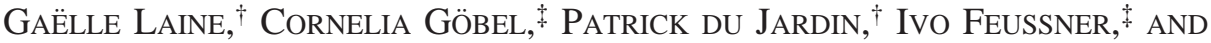 \\ MARIE-LAURE FAUCONNIER $* \dagger$ \\ Plant Biology Unit, Gembloux Agricultural University, Passage des Déportés 2, B-5030 Gembloux, \\ Belgium, and Department of Plant Biochemistry, Albrecht-von-Haller Institute of Plant Sciences, \\ Georg-August-University Göttingen, Justus-von-Liebig-Weg 11, D-37077 Göttingen, Germany
}

\begin{abstract}
Off-flavors frequently appear during the storage of potato flakes. Volatile profile analysis performed by solid-phase microextraction-gas chromatography-mass spectrometry revealed that hexanal is the main compound that appears during the storage period. Hexanal may be a degradation product of linoleic acid formed through linoleic acid hydroperoxide cleavage. Profiles of hexanal precursors were determined from potato flakes at different storage time points. Linoleic acid-derived oxylipins are predominant in potato flakes. The free oxylipins identified, in descending order, are as follows: hexanal, hydroxy polyunsaturated fatty (PUFAs), oxo PUFAs, divinyl ether PUFAs, and hydroperoxy PUFAs. However, the main oxylipins detected were esterified: esterified hydroxy, hydroperoxy, and oxo PUFAs. Oxylipins reveal different evolutions during the storage period. Chiral high-performance liquid chromatography analysis of the precursors of hexanal and other oxylipins revealed a racemic composition that supports the nonenzymatic formation of hexanal and most of the other oxylipins identified.
\end{abstract}

KEYWORDS: Hexanal; off-flavors; potato flakes; lipid oxidation; lipoxygenase

\section{INTRODUCTION}

In the potato industry, potato flakes are a crucial byproduct obtained with a raw material that cannot be valorized by other means. Unfortunately, off-flavors frequently appear during storage of the product leading to economical losses. Few papers on volatile compound analysis in potato products are available $(1-5)$, none of them focusing on potato flake off-flavors from lipid oxidation.

To solve this problem, the origin of these flavors must be identified. With this aim, solid-phase microextraction-gas chromatography-mass spectrometry (SPME-GC-MS) was used in this work to study volatile profile evolution during the storage period. Many methods can be used for the extraction of volatile compounds by GC-MS, among which are liquid-liquid extraction, solid-phase extraction, supercritical fluid extraction, static headspace sampling, or dynamic headspace (purge and trap). SPME has been regarded as a simple, rapid, and economical method requiring no solvent (6). Moreover, the SPME-GC-MS analysis is a useful tool in defining smell perception (7).

As lipid degradation is a major cause of off-flavors and of rancidity in foodstuffs $(8,9)$, a three-step high-performance liquid chromatography (HPLC) method including chiral phase analysis was used to establish the oxylipin profiles (potential

* To whom correspondence should be addressed. Tel: 0032816224 60. Fax: 0032816007 27. E-mail: fauconnier.ml@fsagx.ac.be.

Gembloux Agricultural University.

$\doteqdot$ Georg-August-University Göttingen. substrates). In general, the formation of oxygenated polyunsaturated fatty acids (PUFAs) and metabolites that derive there from, collectively named oxylipins, occurs either by autoxidation or by the action of enzymes such as lipoxygenases (LOXs) and $\alpha$-dioxygenase. The LOX-derived hydroperoxy PUFAs are substrates of at least seven different enzyme families leading to the synthesis of hydroxy PUFAs, divinyl ether PUFAs, allene oxide PUFAs (unstable compounds leading to formation of $\alpha$ and $\gamma$-ketols or 12-oxo-phytodienoic acid), oxo-PUFAs, aldehydes, and trihydroxy PUFAs (10).

To investigate off-flavor formation, fresh potato flakes produced from potato tubers (Solanum tuberosum L. cv. Bintje) were stored for 6 months at $25^{\circ} \mathrm{C}$. Samples were regularly taken to determine SPME-GC-MS volatile and HPLC oxylipin profiles.

\section{MATERIALS AND METHODS}

Materials. Fresh potato flakes were obtained directly from a company and were stored at $25{ }^{\circ} \mathrm{C}$ and at a relative humidity of $50 \%$ during a 6 month period in aluminum bags (day zero was the production day). Samples were taken at nine time points $(4,8,12,14,16,18,20$, 22 , and 24 weeks), ground in liquid nitrogen, and stored at $-80{ }^{\circ} \mathrm{C}$. The commercial formulation of potato flakes was produced from potato tubers (S. tuberosum L. cv. Bintje) and contained ascorbic palmitate and metabisulfite as antioxidants and curcuma and carrot extract as coloring agents. After a few weeks, the appearance of a green note off-flavor was observed. Fresh potato tubers cv. Bintje obtained from local market were used as comparative samples. 
Volatile Compound Analysis. Volatile compounds from potato flakes were extracted by SPME. Each SPME sampling was conducted in triplicate. Approximately $0.5 \mathrm{~g}$ of sample was weighed precisely and was placed in a $20 \mathrm{~mL}$ vial. Five milliliters of milliQ water was added. Vials were hermetically sealed with a PTFE-coated silicone cap, mixed for $1 \mathrm{~min}$, and heated at $35{ }^{\circ} \mathrm{C}$ for $10 \mathrm{~min}$ (equilibrium time). Then, the fused silica fiber coated with an adsorbent phase was exposed to the sample headspace for $1 \mathrm{~h}$ (extraction time). Four fiber types [poly(dimethylsiloxane) (PDMS), poly(dimethylsiloxane)/divinylbenzene (PDMS/DVB), carboxen/poly(dimethylsiloxane) (CAR/PDMS), and carboxen/poly(dimethylsiloxane)/divinylbenzene (CAR/PDMS/ DVB)] were evaluated (all from Supelco, Bellefonte, PA). After sampling, the fiber was immediately thermally desorbed in the gas chromatograph injection port.

The gas chromatography (GC) analysis was performed using a Hewlett-Packard model 6890 gas chromatograph (Palo Alto, CA) fitted with a capillary column CP-WAX $52 \mathrm{CB}(50 \mathrm{~m} \times 0.25 \mathrm{~mm}$ i.d.; film thickness, $0.2 \mu \mathrm{m}$; Varian, Walnut Creek, CA). The injector port was lined with a $0.75 \mathrm{~mm}$ i.d. narrow-bore glass liner (Supelco) and maintained at $270{ }^{\circ} \mathrm{C}$. Helium was used as the carrier gas at a head pressure of $70 \mathrm{kPa}$. The oven temperature was programmed as follows: $35^{\circ} \mathrm{C}$ for $2 \mathrm{~min}$, then to $150{ }^{\circ} \mathrm{C}$ at $5^{\circ} \mathrm{C} / \mathrm{min}$, and finally to $260{ }^{\circ} \mathrm{C}$ at $20^{\circ} \mathrm{C} / \mathrm{min}$, and held for $5 \mathrm{~min}$. The split valve was opened 2 min after injection. The injector temperature was $270{ }^{\circ} \mathrm{C}$.

The mass spectra were obtained using a mass selective detector (Hewlett-Packard model 5973) under electron impact ionization at a voltage of $70 \mathrm{eV}$, and data acquisition was done over an $\mathrm{m} / \mathrm{z}$, range of 35-300. The confirmation of identified compounds was performed by comparing the observed mass spectra with those recorded in the Wiley 275.L Spectrometry Library and by comparison of retention times of standards injected in the same conditions: methanethiol, 2-methyl propanal, 2-methyl butanal, 3-methyl butanal, pentanal, dimethyl disulfide, hexanal, trans-2-heptenal, $\alpha$-ionone, and $\alpha$-curcumene (SigmaAldrich-Fluka, St. Louis, MO), 3-octen-2-one (Acros Organics, New Jersey), and octa-3,5-dien-2-one (Oxford Chemical, Brackley, Northants, United Kingdom). Hexanal was quantified using an external calibration curve with 2-methylpentanal (Sigma-Aldrich-Fluka) as the internal standard (11).

Aldehyde Analysis. Analysis of aldehydes was performed in one replicate as described in ref 12 . Two grams of sample was added to 8 $\mathrm{mL}$ of extraction buffer [methanol/ $\mathrm{HCl} 2 \mathrm{mM}(1: 1, \mathrm{v} / \mathrm{v}), \mathrm{pH} 3.0]$, containing $0.001 \%(\mathrm{w} / \mathrm{v})$ butylated hydroxytoluene (BHT) and $1.2 \mathrm{nmol}$ of di-butyl-acetaldehyde as the internal standard. The extract was homogenized for $45 \mathrm{~s}$ and centrifuged at $1300 \mathrm{~g}$ at $4{ }^{\circ} \mathrm{C}$ for $10 \mathrm{~min}$. The collected clear upper phase was stirred with $1 \mathrm{~mL}$ of dinitro phenylhydrazine $(\mathrm{DNPH})$ reagent $[0.2 \%(\mathrm{w} / \mathrm{v})$ in $1 \mathrm{M} \mathrm{HCl}]$ at room temperature for $1 \mathrm{~h}$. The reaction mixture was extracted two times with $5 \mathrm{~mL}$ of $n$-hexane, and the collected organic phases were dried under a stream of nitrogen. DNPH derivatives were redissolved in acetonitrile/ water $(3: 2, \mathrm{v} / \mathrm{v})$.

Reverse phase (RP) HPLC analysis was carried out on an Agilent 1100 HPLC System (Palo Alto, CA) coupled to a diode array detector with a Ultrasphere $\mathrm{C}-18$ column $(250 \mathrm{~mm} \times 2 \mathrm{~mm}, 5 \mu \mathrm{m}$ particle size; Beckman, Fullerton, CA) using the following binary gradient system, solvent A [acetonitrile/water (50:50, v/v)] and solvent B [acetonitrile/ water $(80: 20, v / v)]$ with the gradient program $15 \%$ solvent $B$ for 15 min, followed by a linear increase of solvent B up to $66.6 \%$ within 5 min, by a linear increase of solvent B up to $100 \%$ within 13.4 min and held for $16.6 \mathrm{~min}$, by a linear decrease up to $15 \%$ solvent B within 5 min, and finally by an isocratic postrun at $15 \%$ solvent B for 5 min. The flow rate was $0.3 \mathrm{~mL} / \mathrm{min}$, and the injection volume was $50 \mu \mathrm{L}$.

Determination of LOX Activity. For the determination of LOX activity, two methods were used. Spectrophotometer-based analysis (234 $\mathrm{nm}$ ) was performed as described in ref 13 using $2 \mathrm{~g}$ of powdered sample and linoleic acid as the substrate. Three extracts and five measurements on each extract were carried out. The analysis was performed on potato flake samples stored for 4 weeks. Fresh potato tubers were used as a positive control, and boiled extracts $\left(30 \mathrm{~min}, 95^{\circ} \mathrm{C}\right)$ of these potato tubers were used as a negative control.

HPLC-based analysis was performed as described in ref 14 on potato flakes stored for, respectively, 4 and 16 weeks and on fresh potato tubers as positive controls. Approximately $0.5 \mathrm{~g}$ of sample was added to $1.6 \mathrm{~mL}$ of lysis buffer $(90 \mathrm{mM}$ Tris/ $\mathrm{HCl}, \mathrm{pH} 9.5,10 \%$ glycerol, 500 $\mathrm{mM} \mathrm{NaCl}$, and 0.1 Tween 20$)$ and $2.4 \mathrm{~mL}$ of Tris buffer $(100 \mathrm{mM}$ Tris/HCl, $\mathrm{pH}$ 7.5) on ice. After homogenization with an Ultra Turrax under a stream of argon for $30 \mathrm{~s}$, oxygenation of linolenic acid was carried out by incubating LOX preparations with the substrate $(1 \mu \mathrm{mol})$ for $30 \mathrm{~min}$ at room temperature. Five micromoles of $\mathrm{SnCl}_{2}$ in methanol was added to the reaction medium. The mixture was incubated at room temperature for $10 \mathrm{~min}$, and $150 \mu \mathrm{L}$ of acetic acid was added. The reaction products were extracted twice with one volume of chloroform and analyzed by HPLC (see Oxylipin Profiling).

Fatty Acid Analysis. Fatty acids were extracted in two replicates and analyzed as described in refs $14-16$. For the extraction of free fatty acids, heptadecanoic acid was used as an internal standard and about $2 \mathrm{~g}$ of frozen material was added to $20 \mathrm{~mL}$ of extraction medium [isohexane/2-propanol, 3:2 (v/v) with 0.0025\% (w/v) BHT]. For the extraction of esterified fatty acids, triheptadecanoic acid was used as an internal standard and about $0.5 \mathrm{~g}$ of frozen material was added to $20 \mathrm{~mL}$ of extraction medium. After homogenization, the extract was centrifuged at $1300 \mathrm{~g}$ at $4{ }^{\circ} \mathrm{C}$ for $10 \mathrm{~min}$. The clear upper phase was collected, and a $6.7 \%(\mathrm{w} / \mathrm{v})$ solution of potassium sulfate was added to $32.5 \mathrm{~mL}$. After vigorous shaking, the extract was centrifuged at $1300 \mathrm{~g}$ at $4{ }^{\circ} \mathrm{C}$ for $10 \mathrm{~min}$. The upper hexane-rich layer containing fatty acids was removed. Subsequently, esterified fatty acids were transmethylated with sodium methoxide, and free fatty acids were methylated with trimethylsilyldiazomethane. The analysis of the corresponding fatty acid methyl esters was performed with an Agilent 6890 gas chromatograph fitted with a capillary DB column $(30 \mathrm{~m} \times 0.25 \mathrm{~mm} ; 0.25 \mu \mathrm{m}$ coating thickness; J\&W Scientific, Agilent). Helium was used as a carrier gas $(1 \mathrm{~mL} / \mathrm{min})$. The temperature gradient was $150{ }^{\circ} \mathrm{C}$ for $1 \mathrm{~min}, 150-$ $200{ }^{\circ} \mathrm{C}$ at $8 \mathrm{~K} / \mathrm{min}, 200-250{ }^{\circ} \mathrm{C}$ at $25 \mathrm{~K} / \mathrm{min}$, and $250{ }^{\circ} \mathrm{C}$ for $6 \mathrm{~min}$.

Oxylipin Profiling. LOX-derived products were extracted in two replicates and analyzed as described in refs $14-16$. For the extraction of free oxylipins, $(6 Z, 9 Z, 11 E, 13 \mathrm{~S})$-13-hydroxy-6,9,11-octadecatrienoic acid was used as an internal standard and about $2 \mathrm{~g}$ of frozen material was added to $20 \mathrm{~mL}$ of extraction medium (see above). For the extraction of esterified oxylipins, triricinoleate was used as an internal standard and about $0.5 \mathrm{~g}$ of frozen material was added to $20 \mathrm{~mL}$ of extraction medium. After homogenization, the extract was centrifuged at $1300 \mathrm{~g}$ at $4{ }^{\circ} \mathrm{C}$ for $10 \mathrm{~min}$. The clear upper phase was collected, and a $6.7 \%(\mathrm{w} / \mathrm{v})$ solution of potassium sulfate was added leaving the volume to $32.5 \mathrm{~mL}$. After vigorous shaking, the extract was centrifuged at $1300 \mathrm{~g}$ at $4{ }^{\circ} \mathrm{C}$ for $10 \mathrm{~min}$. The upper hexane-rich layer containing the oxilipin fatty acid derivatives was removed. Subsequently, esterified oxylipins were transmethylated with sodium methoxide.

In a first step, oxylipins were purified by RP-HPLC. This was performed on an EC250/2 Nucleosil 120-5 C18 column $(250 \mathrm{~mm} \times$ $2.1 \mathrm{~mm}, 5 \mu \mathrm{m}$ particle size; Macherey \& Nagel, Easton, PA) with the following binary gradient system: solvent A [methanol:water:acetic acid (75:15:0.1, v/v)] and solvent B [methanol:water:acetic acid (100: $0: 0.1, \mathrm{v} / \mathrm{v})]$ with the gradient program $20 \%$ solvent B for $10 \mathrm{~min}$, followed by a linear increase of solvent B up to $40 \%$ within 28 min, by a linear increase of solvent B up to $100 \%$ within 30 min and held for $15 \mathrm{~min}$, by a linear decrease up to $20 \%$ solvent B within $5 \mathrm{~min}$, and finally by an isocratic postrun at $15 \%$ solvent B for $6 \mathrm{~min}$. The flow rate was $0.18 \mathrm{~mL} / \mathrm{min}$ up to $30 \mathrm{~min}$ and increased linearly to $0.36 \mathrm{~mL} / \mathrm{min}$ within $35 \mathrm{~min}$, held within $10 \mathrm{~min}$, followed by a linear decrease up to $0.18 \mathrm{~mL} / \mathrm{min}$ within $50 \mathrm{~min}$ and a postrun for $6 \mathrm{~min}$. The injection volume was $80 \mu \mathrm{L}$. Straight-phase HPLC for separation of hydroperoxy fatty acids, hydroxy fatty acids, and keto fatty acids was performed on a Zorbax Rx-SIL column $(150 \mathrm{~mm} \times 2.1 \mathrm{~mm}, 5$ $\mu \mathrm{m}$ particle size, Agilent) with $n$-hexane/2-propanol/acetic acid (100: $1: 0.1, \mathrm{v} / \mathrm{v} / \mathrm{v}$ ) as a solvent system at a flow rate of $0.2 \mathrm{~mL} / \mathrm{min}$. The injection volume was $25 \mu \mathrm{L}$. For detection of the hydroperoxy and hydroxy fatty acids and keto fatty acids, the absorbance was recorded at 234 and $270 \mathrm{~nm}$, respectively. The enantiomeric composition of the hydroxy fatty acids was analyzed by chiral-phase HPLC on a Chiral OD-H column $(150 \mathrm{~mm} \times 2.1 \mathrm{~mm}, 5 \mu \mathrm{m}$ particle size; Baker, Phillisburg, NJ) with $n$-hexane/2-propanol/acetic acid (100:5:0.1, v/v/ v) as a solvent system at a flow rate of $0.1 \mathrm{~mL} / \mathrm{min}$. The injection volume was $10 \mu \mathrm{L}$. 
Table 1. Volatile Compounds Identified in Potato Flakes

\begin{tabular}{|c|c|c|}
\hline compounds & RT & flavor (29) \\
\hline methanethiol $^{a}$ & 1.28 & rotten cabbage \\
\hline 2-methyl propanal ${ }^{a}$ & 1.56 & fruity, banana-like, "overripe fruitlike" \\
\hline 3-methyl butanala & 2.21 & peach-like, heavy-fruity \\
\hline 2-methyl butanala & 2.32 & $\begin{array}{l}\text { fruity-"fermented" with a peculiar } \\
\text { note resembling that of } \\
\text { roasted cocoa or coffee }\end{array}$ \\
\hline pentanal $^{a}$ & 2.72 & dry-fruity, musty, nutlike \\
\hline dimethyl disulfide ${ }^{a}$ & 3.49 & onionlike \\
\hline hexanal $^{a}$ & 4.71 & $\begin{array}{l}\text { green odor, freshly cut grass and } \\
\text { unripe fruits (apple and plum) }\end{array}$ \\
\hline 2-heptenala ${ }^{a}$ & 9.17 & vegetables-juicy-green \\
\hline $\begin{array}{l}\text { 2,2,4,6,6-pentamethyl } \\
\text { heptane }\end{array}$ & 10.19 & \\
\hline 3-octen-2-one ${ }^{a}$ & 11.77 & fatty, green fruit, nutty, spicy, unripe \\
\hline 3,5-octadien-2-one ${ }^{a}$ & 12.79 & fatty, fruity, hay, oxidized \\
\hline$\alpha$-ionone ${ }^{a}$ & 22.91 & warm woody, balsamic-floral odor \\
\hline$\alpha$-curcumene ${ }^{a}$ & 24.35 & freshly grassy \\
\hline
\end{tabular}

${ }^{a}$ Identity of compounds confirmed by GC-MC analysis of standards; the rest of the compounds were tentatively identified based on WILEY mass spectra library search.

GC-MS-based analysis was also used for oxilipin profiling as described in ref 14 . For the identification of 2-hydroxy fatty acids and trihydroxy fatty acids, about $2 \mathrm{~g}$ of frozen material was used and the internal standards were $\mathrm{D}_{3}$-2-hydroxy-octadecatrienoic acid and $\mathrm{D}_{6^{-}}$ $9,10,11$, trihydroxy-octadecadienoic.

Data Analysis. On figures, the values correspond to the mean and the error bars correspond to the standard deviations.

\section{RESULTS AND DISCUSSION}

Volatile Compound Analysis. Volatile compounds from potato flakes were extracted by SPME. Four types of fibers (PDMS, PDMS/DVB, CAR/PDMS, and CAR/PDMS/DVB) were tested under the same conditions to evaluate the more adapted one [adsorption of the greatest amount (expressed as peak areas) and the highest number of compounds]. Best results were obtained with the CAR/PDMS/DVB fiber, which is in good accordance with refs 1,8 , and 17 .
Analysis of the volatile SPME profiles obtained for the different time points of potato flakes reveals only a few volatile compounds and very low levels of these compounds as compared to volatile compounds extracted from fried and boiled potatoes (4). Hexanal is mainly identified. Beside hexanal, 12 additional volatile compounds were also identified in very small amounts (Table 1). So, hexanal may be associated with offflavors in potato flakes. Hexanal has a low odor threshold (479 ppb in deionized water; 18) and is the only aldehyde formed from both the 9- and the 13-hydroperoxide of linoleic acid at least by chemical reactions. Hexanal may be the direct product of the chemical fragmentation of the 13-hydroperoxide of linoleic acid, or it may derive from 2,4 decadienal that may be a product of chemical oxidation of 9-hydroperoxy linoleic acid (HPOD) $(19,20)$. Hexanal was quantified in potato flakes during a storage period by using the SPME-based method. For this purpose, a calibration curve was generated $\left(R^{2}=0.90, n=5\right)$ using 2-methylpentanal as an internal standard (11). Hexanal release is detectable from the 12 th week on, and it steadily increases during the storage period (Figure 1). Almost undetectable after 12 weeks of storage, the released hexanal amount reaches $78 \mathrm{nmol} / \mathrm{g} \mathrm{FW}$ after 24 weeks.

Potato tubers contain mainly linoleic acid as PUFAs and the major LOX activity in tubers forms 9-derivatives, the precursors of enzymatic C-9 aldehyde formation $(21,22)$. Surprisingly, we did not find other aldehyde compounds such as nonenal. However, hexanal may be the preferred product of 9-hydroperoxides from chemical reactions as well. Moreover, the SPME technique may discriminate as the fibers adsorb more preferentially the most volatile compounds. Despite this disadvantage, the technique is well-adapted to define smell perception (7). An alternative to circumvent this possible drawback is the analysis of aldehydes from potato flake extracts by HPLC after derivatization with DNPH (13).

Aldehyde Analysis. HPLC analysis mainly confirmed the results obtained by SPME-GC-MS (data not shown). Indeed, hexanal is the major aldehyde identified in potato flakes, but the amount of hexanal that presumably stayed in the flakes (results from HPLC analysis) is lower than the amount in the

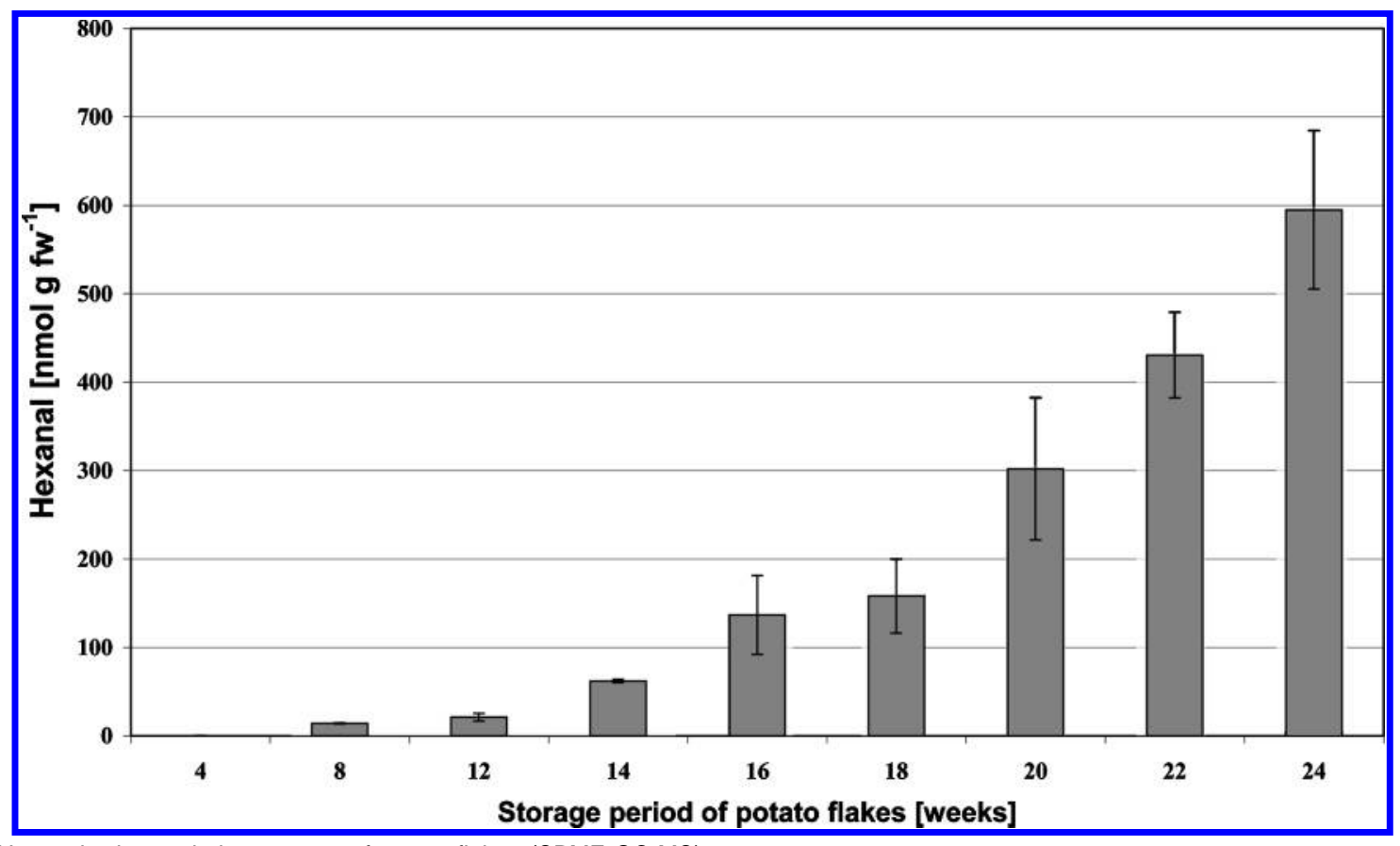

Figure 1. Hexanal release during storage of potato flakes (SPME-GC-MS). 


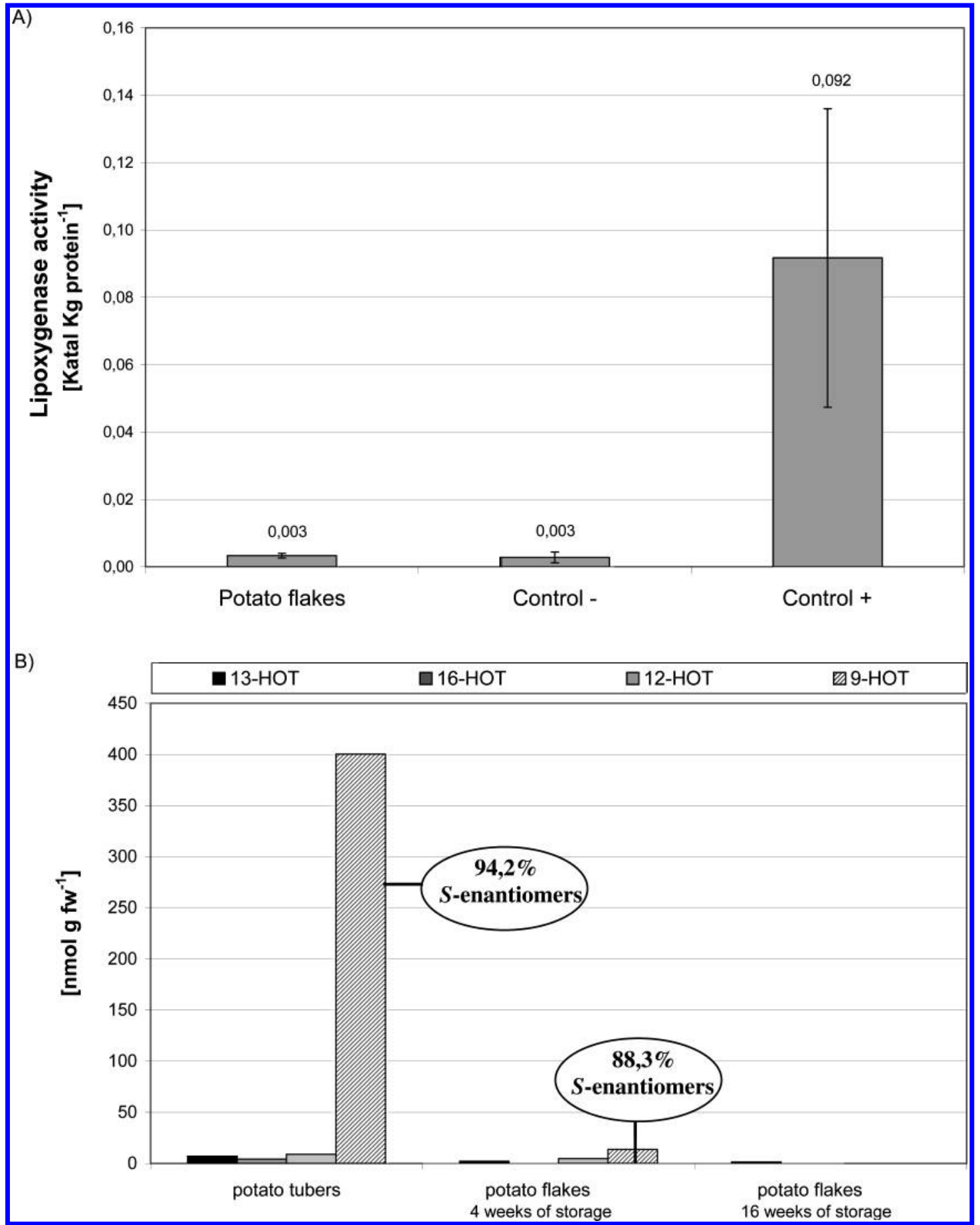

Figure 2. (A) LOX activity in potato flakes, boiled potato tubers (control -), and potato tubers (control +). (B) Fatty acid degradation products obtained after incubating the enzymatic extracts with acid linolenic and percentage of $S$-enantiomers of 9-HOT.

gas phase obtained by SPME-GC-MS. Hence, both techniques provide interesting results because different substance pools were measured. Heptanal and hexenal were also identified and quantified by HPLC; heptenal, heptadienal, nonanal, nonenal, and nonadienal were tentatively identified as minor products. Except heptenal, none of these compounds have been identified by SPME-GC-MS.

The amount of hexanal and heptanal increases during storage. Considering these results, enzymatic formation of hexanal in potato flakes may be questioned. To address this question, oxylipin profiling was performed.

Determination of LOX Activity. At first, a spectrophotometric method was used to search for LOX activity and no LOX activity could be detected (Figure 2A). Then, a second qualitative HPLC-based analysis method was performed to either confirm or reject this result. As compared with positive controls (fresh potato tuber), very small amounts of LOX products were detected in 4 week old potato flakes (Figure 2B). Moreover, the lower $S / R$ ratio for 9-hydroxy-linolenic acid (9-HOT) may be indicative of a higher proportion of nonenzymatic origin of this compound [the level of 13-hydroxy-linolenic acid (13-HOT) was too low to perform a chiral analysis]. The enzymatic formation of a compound is determined from a $S$ enantiomer percentage higher than $95 \%$ (15). So, it may be concluded that there is almost no LOX activity in flakes. This result is not surprising considering the transformation process of potato 

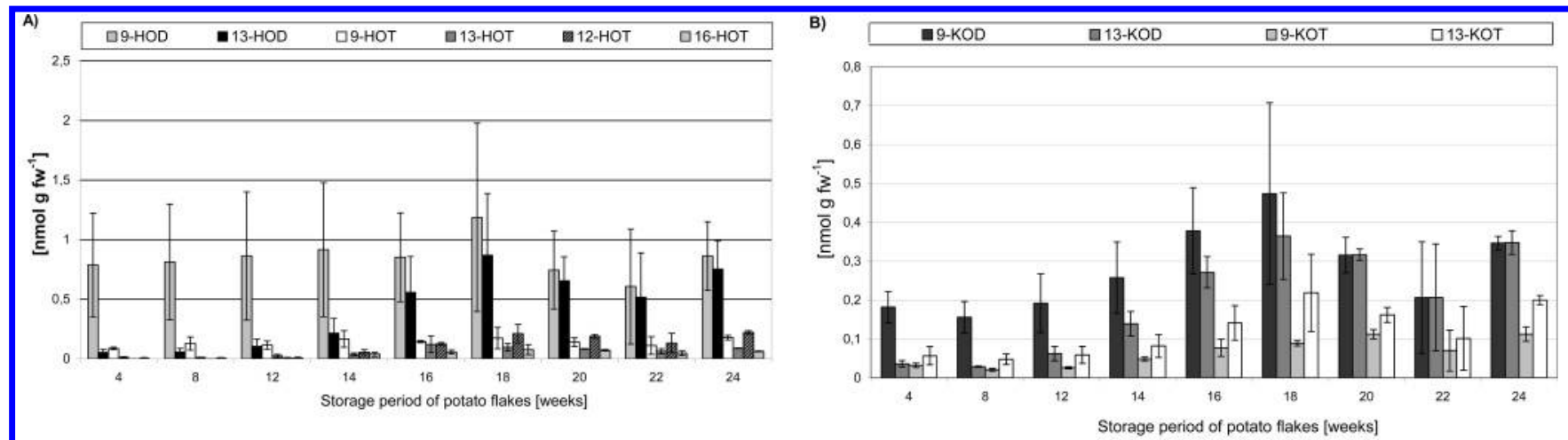

c
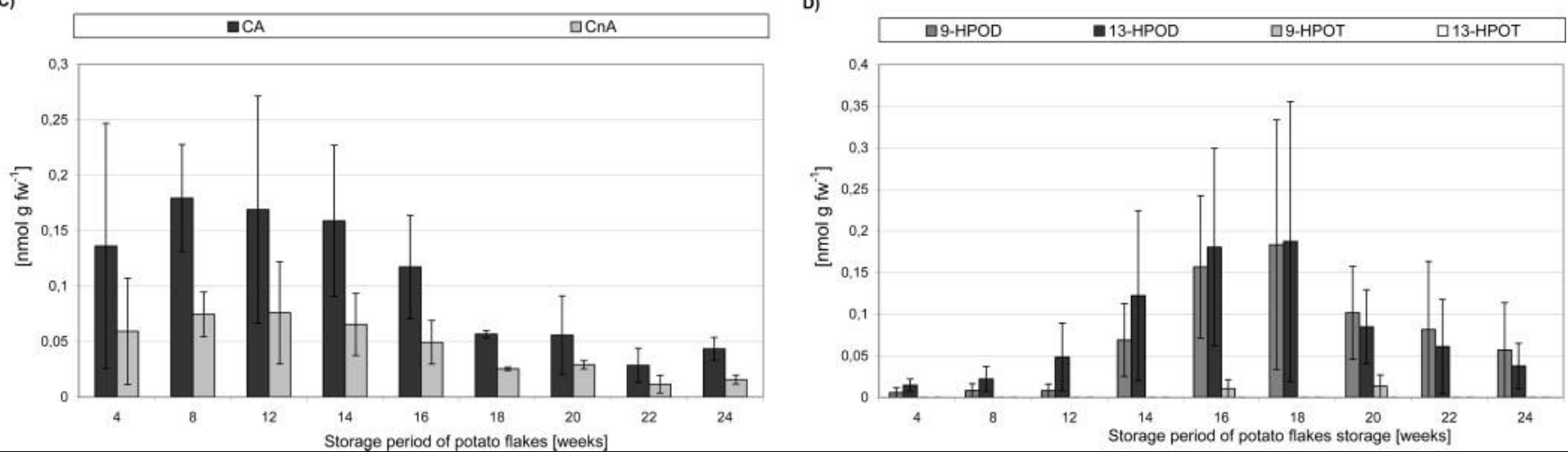

Figure 3. Free oxylipin profiling during storage of potato flakes. (A) Hydroxy PUFAs, (B) oxo PUFAs, (C) divinyl ether PUFAs, and (D) hydroperoxy PUFAs.

tubers into potato flakes that includes a blanching and a cooking step. These high temperatures may be sufficient to inactivate LOX activity $(23,24)$.

Fatty Acid Profiling. The main free fatty acid is linoleic acid. It accumulates to about $0.1 \mu \mathrm{mol} / \mathrm{g} \mathrm{FW}$ independent of the storage time. The amount of all other fatty acid is at least one magnitude less (data not shown) and in accordance with ref 22. As expected, esterified fatty acids exist in 20-100 times higher amounts than free fatty acids as was observed in potato tubers (15). Because of the addition of triglycerides as an emulsifier during the transformation process of potato flakes, palmitic and stearic acids were the main esterified fatty acids (ranging from 4 to $6 \mu \mathrm{mol} / \mathrm{g} \mathrm{FW}$ ) since these fatty acids derive from the potato tissue and from the emulsifier. No significant change in fatty acid amount was observed during storage of potato flakes.

Oxylipin Profiling. The main free oxylipins identified, in descending order, are hexanal (see volatile and aldehyde compounds), hydroxy PUFAs, oxo PUFAs, divinyl ether PUFAs, and hydroperoxy PUFAs. The amount of linoleic acidderived oxylipins in general is higher than the amount of $\alpha$-linolenic acid-derived oxylipins. This is in accordance with the predominant occurrence of linoleic acid in potato tubers.

The hydroxy PUFAs were the main oxylipins analyzed (Figure 3A). The amount of 13-hydroxy-linoleic acid (13-HOD) increases from the 14th to the 18th week from about 0.05 to $0.8 \mathrm{nmol} / \mathrm{g} \mathrm{FW}$. Then, it remained at a level of about $0.7 \mathrm{nmol} / \mathrm{g}$ FW. Assuming that 13-HOD is the reduction product of 13hydroperoxy-linoleic acid (13-HPOD), which is in addition to one of the precursors of hexanal formation, it is remarkable that its increase over time is comparable with that of hexanal (Figure 1 vs 3A). All other hydroxy PUFAs [9-, 12-, 13-, and 16-hydroxy-linolenic acid (HOT)] increased steadily from about 0.05 to $0.1 \mathrm{nmol} / \mathrm{g} \mathrm{FW}$ during storage in potato flakes.
Chiral analysis of 9-HOD and 13-HOD showed the presence of $72.0 \pm 8.7$ and $48.5 \pm 1.7 \% S$ enantiomers, respectively. This indicates the nonenzymatic formation of these compounds. Considering that HODs are HPOD-derived products, a nonenzymatic formation of hexanal can be proposed.

In contrast to aldehydes and hydroxy PUFAs, the oxo PUFAs accumulate transiently peaking at about 18 weeks of storage (Figure 3B). The amount of linoleic acid-derived oxylipins is again higher than the amount of linolenic acid-derived oxylipins, and the level of 9-oxo-linoleic acid (9-KOD) was the highest increasing from about 0.15 to $0.5 \mathrm{nmol} / \mathrm{g} \mathrm{FW}$, followed by the amount of $13-\mathrm{KOD}$ increasing from about 0.03 to $0.4 \mathrm{nmol} / \mathrm{g}$ FW. The other two oxo PUFAs detected [9- and 13-oxolinolenic acid (KOT)] ranged from about 0.02 to $0.2 \mathrm{nmol} / \mathrm{g}$ FW during storage.

Interestingly, the divinyl ether PUFAs colneleic (CA) and colnelenic acid ( $\mathrm{CnA})$ accumulate again with a different kinetic. They peak transiently at about 8-12 weeks of storage (Figure 3C), and the amount of the linoleic acid-derived derivative is again higher than the amount of $\mathrm{CnA}$ that derives from linolenic acid. The level of CA was the highest at about $0.24 \mathrm{nmol} / \mathrm{g}$ $\mathrm{FW}$, decreasing then to levels of about $0.04 \mathrm{nmol} / \mathrm{g} \mathrm{FW}$. CnA decreased from a level of about 0.1 to $0.01 \mathrm{nmol} / \mathrm{g}$ FW during storage in potato flakes.

Only a small amount of hydroperoxy PUFAs (mainly 9- and 13-HPOD) ranging from 0.01 to $0.2 \mathrm{nmol} / \mathrm{g} \mathrm{FW}$ accumulates transiently between week 14 and week 20 (Figure 3D). They show the same transient accumulation like that observed for the oxo PUFAs (Figure 3B vs D). Although a significant proportion of hydroperoxy PUFAs may be decomposed during our work up procedure, their specific time-dependent accumulation that is different from the kinetics we observed for most of the other oxylipins supports their specific occurrence in the 


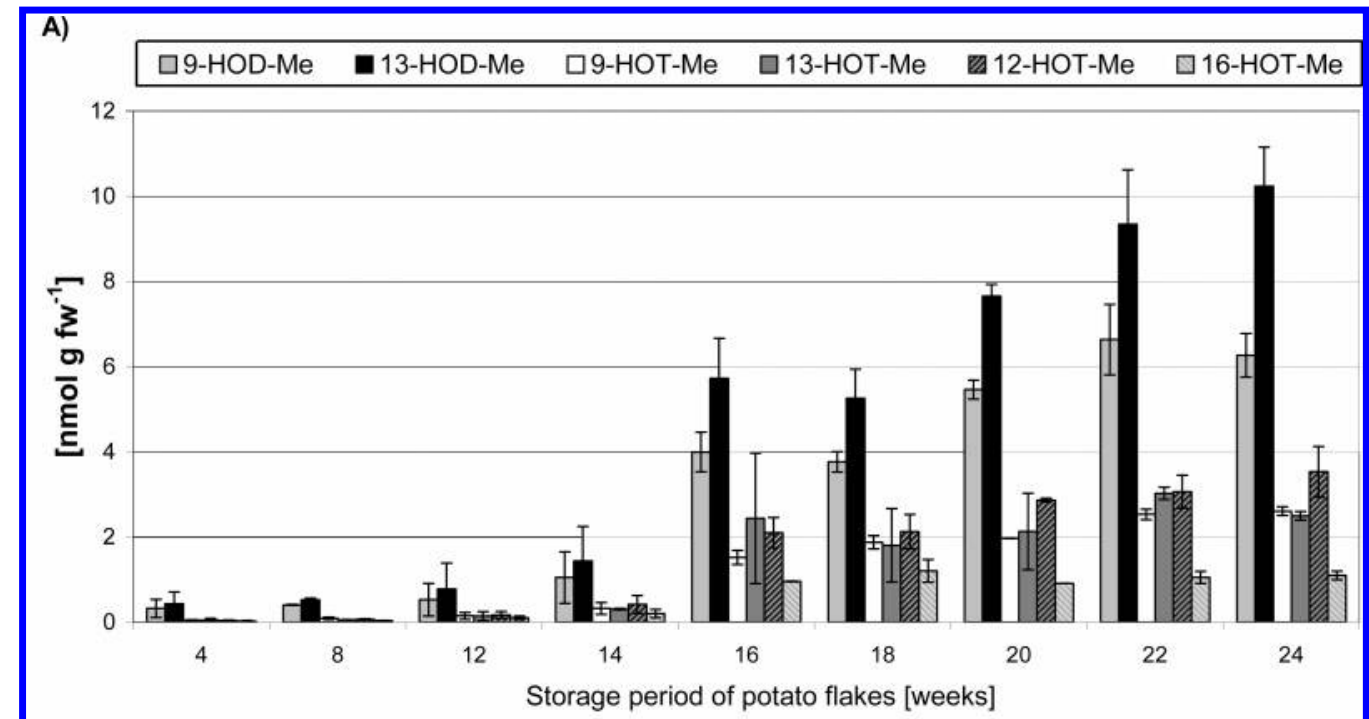

B)

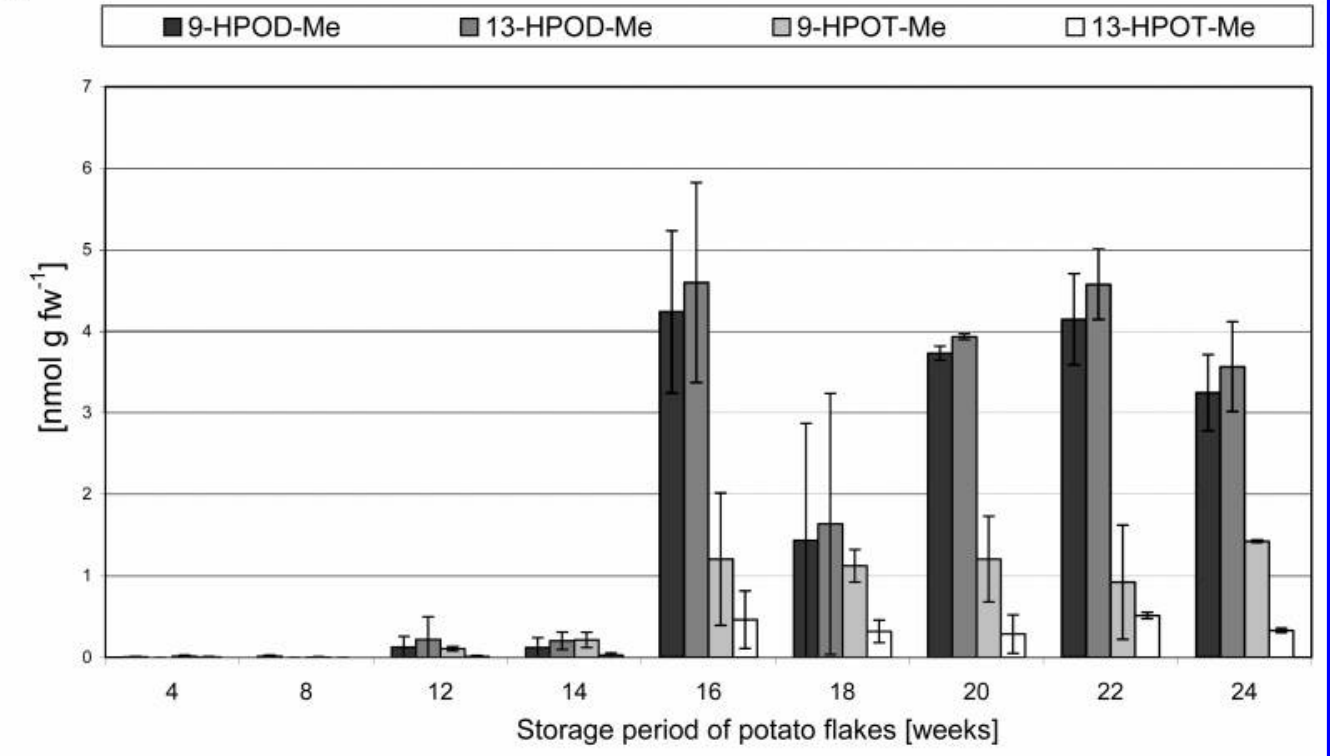

C)
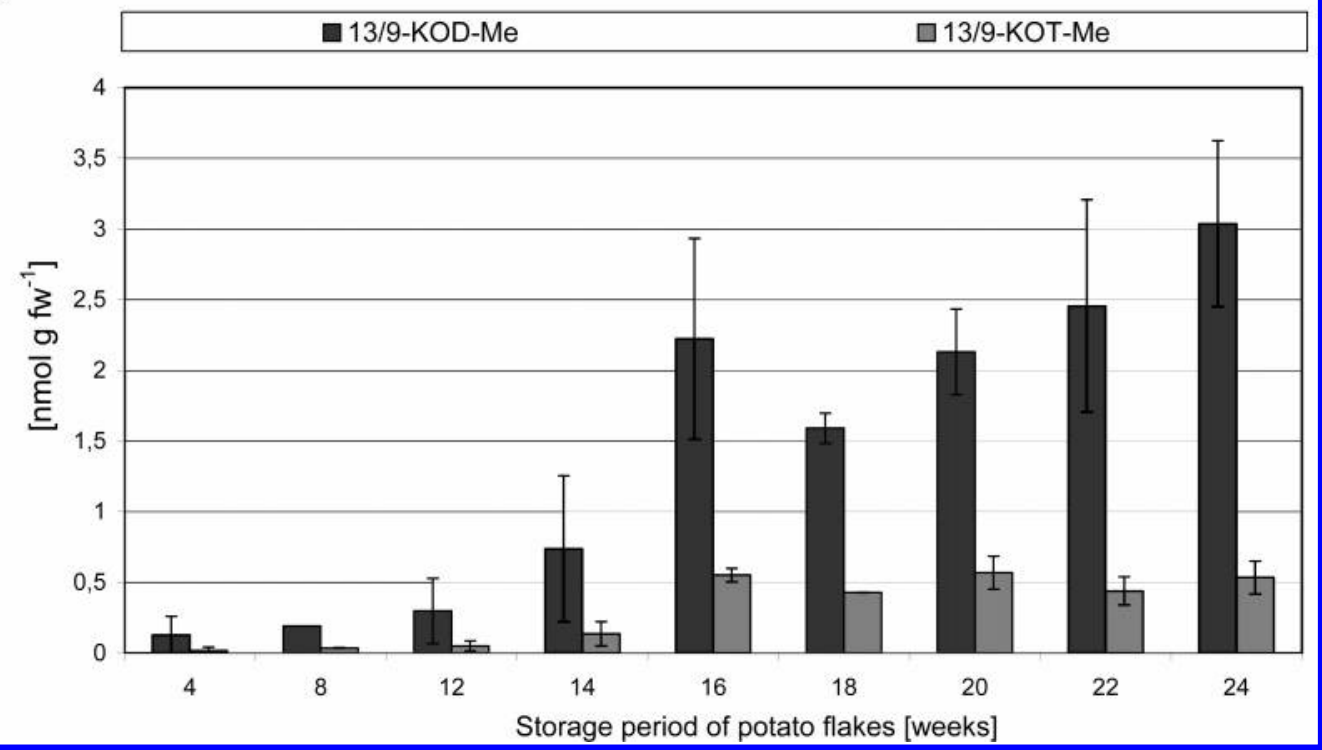

Figure 4. Esterified oxylipin profiling during storage of potato flakes. (A) Hydroxy PUFAs, (B) oxo PUFAs, and (C) hydroperoxy PUFAs. 
samples. These results and the fact that potatoes contain large amounts of ascorbate (25) suggest that the hydroperoxy fatty acids are rapidly converted mainly into the corresponding hydroxy PUFAs (Figure 3A).

Taken together, the major nonesterified oxylipin is hexanal in stored potato flakes and it derives most likely from oxidative chemical decomposition of linoleic acid. After 24 weeks, its amount reaches up to $20 \%$ of that of its precursor linoleic acid. As described in ref $26,0.0001 \%$ of oxidized fatty acid is sufficient to produce off-flavor components. The amount of all other nonesterified oxylipins is about 100-fold lower. Moreover, divinyl ether PUFAs seem to be the only nonesterified oxylipins that are of enzymatic origin. Because the amount of these oxylipins decreases during the storage period, one may conclude that they derive from metabolic processes, i.e., by the combined action of 9-LOX and divinyl ether synthase during tuber formation (10). The question that remains open is into which products they are degraded. Under mild acidic conditions, CA and $\mathrm{CnA}$ may be hydrolyzed to nonenal and nonadienal and their corresponding oxo fatty acids, but we failed to detect any significant accumulation of these aldehydes (27). In summary, we observe four different kinetics for the temporal appearance of nonesterified oxylipins. (i) 9-HOD: It may accumulate during tuber formation by the action of one or more tuber LOXs, and the $S$ isomer isomerizes during storage into the racemate. Moreover, its amount stays almost constant during storage. This suggests that this oxylipin is a rather stable metabolite in potato flakes. (ii) Divinyl ether PUFAs: They accumulate most likely during tuber formation as well, but their amount decreases during the early stages of storage. Their degradation products in potato flakes are unknown so far, and it will interesting to analyze their metabolism in more detail. (iii) Hydroperoxy fatty acids: They accumulate transiently during the storage time, peaking at 18 weeks. Afterward, they possibly decompose into hydroxy and oxo PUFAs. (iv) Hydroxy and oxo PUFAs: They start to accumulate from week 14 on reaching their maximal amounts around week 18 . Whether they are further degraded remains to be open so far as well, but as discussed for 9-HOD, they seem to be rather stable, since their amounts do not decrease during longer storage periods.

Because the major proportion of PUFAs resides in the fraction esterified fatty acids and mainly oxylipins derived from autoxidation were found at the level of nonesterified oxylipins, we inspected next the fraction esterified fatty acids for oxylipins. As esterified oxylipins, we detected hydroxy, hydroperoxy, and oxo PUFAs but no divinyl ether PUFAs (Figure 4). The main esterified oxylipins are hydroxy PUFAs and, within this group, the linoleic acid-derived 13-HODME (Figure 4A). This is in contrast to the fraction of nonesterified hydroxy PUFAs where 9-HOD was the major metabolite. All esterified hydroxy PUFAs increased steadily from week 14. Esterified 13-HOD increases from about 0.4 to $10 \mathrm{nmol} / \mathrm{g} \mathrm{FW}, 13-\mathrm{HOT}$ increases from about 0.05 to $2 \mathrm{nmol} / \mathrm{g} \mathrm{FW}, 16-\mathrm{HOT}$ increases from about 0.03 to 1 $\mathrm{nmol} / \mathrm{g} \mathrm{FW}, 12-\mathrm{HOT}$ increases from about 0.04 to $3.5 \mathrm{nmol} / \mathrm{g}$ FW, 9-HOD increases from about 0.3 to $6.6 \mathrm{nmol} / \mathrm{g} \mathrm{FW}$, and 9-HOT increases from about 0.05 to $2.5 \mathrm{nmol} / \mathrm{g} \mathrm{FW}$. Interestingly, we detected not only derivatives that derive from linoleic acid but the hydroxides from linolenic acid as well. Moreover, not only positional isomers that may derive from the action of LOXs, but also isomers that are formed only by chemical oxidation, 12- and 16-HOT (28). 9-HODMe, 9-HOTMe, 13HODMe, and 13-HOTMe, consisted of 52.2 $\pm 3.6,64.8 \pm 14.9$, $48.5 \pm 3.4$, and $60.0 \pm 11.4 \% S$ enantiomers, respectively. Like most nonesterified oxylipins, all esterified oxylipins may be produced nonenzymatically.

Contrary to free fatty acids, there are more hydroperoxy fatty acids than oxo fatty acids (Figure $\mathbf{4 B}$ vs $\mathbf{C}$ ). Esterified hydroperoxy PUFAs increased from week 18 on and remained at that level till the end of our time course. 13-HPODMe increases from about 0.2 to $4.2 \mathrm{nmol} / \mathrm{g} \mathrm{FW}, 13-\mathrm{HPOTMe}$ increases from about 0.01 to $4.5 \mathrm{nmol} / \mathrm{g} \mathrm{FW}$, 9-HPODMe increases from about 0.01 to $4.0 \mathrm{nmol} / \mathrm{g} \mathrm{FW}$, and 9 -HPOTMe increases from about 0.01 to $1.0 \mathrm{nmol} / \mathrm{g} \mathrm{FW}$ (Figure 4B). Esterified oxo PUFAs increased from week 12. Because we can separate the 9- and 13-derivatives of either KODMe and KOTMe, respectively, we expressed their amounts as sums out of both. 9/13-KODMe increases from about 0.15 to $2.5 \mathrm{nmol} / \mathrm{g}$ $\mathrm{FW}$, and 9/13-KOTMe increases from about 0.025 to $0.5 \mathrm{nmol} / \mathrm{g}$ FW (Figure 4C).

Trihydroxy fatty acids were not found in potato flakes suggesting that epoxy alcohol synthase is not active or more complex oxidation reactions did not take place. Roughanic acid (C16:3)-derived oxylipins were not found in accordance with the absence of this fatty acid in potato flakes. Dihydroxy fatty acids and 2-hydroxy fatty acids were not found suggesting that there is no action of $\alpha$-dioxygenase in potato flakes or any other corresponding chemical oxidation. In summary, comparing the level of free PUFAs with that of nonesterified oxylipins, we found that after 18 weeks of storage the amount of oxylipins (excluding aldehydes) accounts for about $1 \%$ of the amount of PUFAs. When comparing the level of esterified PUFAs with that of esterified oxylipins, the latter account for roughly about $0.1 \%$. However, because the flakes contain about 10-20-fold more esterified fatty acid derivatives, the amount of oxylipins was about the same in both fractions.

To conclude, in this study, hexanal was identified as the main compound responsible for off-flavors in potato flakes during storage. This compound has already been reported as an indicator of lipid oxidation. The nonenzymatic formation of hexanal from hydroperoxy fatty acid may be concluded. From an industrial viewpoint, these results can be exploited to reduce off-flavors appearing during the storage of potato flakes. However, further investigations are necessary to correlate these results with sensory data, to understand the autoxidation mechanism, and to determine formula or process modifications that can avoid this volatile formation.

\section{ABBREVIATIONS USED}

LOX, lipoxygenase; PUFAs, polyunsaturated fatty acids; HOD, hydroxy linoleic acid; HOT, hydroxy linolenic acid; KOD, keto linoleic acid; KOT, keto linolenic acid; HPOD, hydroperoxy linoleic acid; HPOT, hydroperoxy linolenic acid; Me, esterified.

\section{ACKNOWLEDGMENT}

We gratefully thank Pr. M. Marlier of general and organic Chemistry Unit (FUSAGx, Belgium) for his efficient help and Danny Trisman and Vincent Hote for technical assistance and Mats Hamberg (Stockholm, Sweden) and Otto Miersch (Halle, Germany) for providing us with deuterated standards.

\section{LITERATURE CITED}

(1) Sanches-Silva, A.; Lopez-Hernandez, J.; Paseiro-Losada, P. Profiling flavor compounds of potato crisps during storage using solid-phase microextraction. J. Chromatogr. A 2005, 1064, 239245. 
(2) van Loon, W. A. M.; Linssen, J. P. H.; Legger, A.; Posthumus, M. A.; Voragen, A. G. J. Identification and olfactometry of French fries flavor extracted at mouth conditions. Food Chem. 2005, 90, 417-425.

(3) Petersen, M. A.; Poll, L.; Larsen, L. M. Identification of compounds contributing to boiled potato off-flavor ("POF"). Lebensm.-Wiss. Technol. 1999, 32, 32-40.

(4) Sapers, G. M. Flavor and stability of dehydrated potato products. J. Agric. Food Chem. 1975, 23, 1027-1032.

(5) Boggs, M. M.; Buttery, R. G.; Venstrom, D. W.; Belote, M. L. Relation of hexanal in vapor above stored potato granules to subjective flavor estimates. J. Food Sci. 1964, 29, 487-489.

(6) Moon, S.-Y.; Li-Chan, E. C. Y. Development of solid-phase microextraction methodology for analysis of headspace volatile compounds in simulated beef flavor. Food Chem. 2004, 88, 141149.

(7) Frank, D. C.; Owen, C. M.; Patterson, J. Solid-phase microextraction (SPME) combined with gas-chromatography and olfactometry-mass spectrometry for characterization of cheese aroma compounds. Lebensm.-Wiss. Technol. 2004, 37, 139-154.

(8) Sanches-Silva, A.; Rodriguez-Bernaldo de Quiros, A.; LopezHernandez, J.; Paseiro-Losada, P. Determination of hexanal as indicator of the lipidic oxidation state in potato crisps using gas chromatography and high-performance liquid chromatography. J. Chromatogr. A 2004, 1046, 75-81.

(9) Gardner, H. W.; Grove, M. J.; Salch, Y. P. Enzymic pathway to ethyl vinyl ketone and 2-pentenal in soybean preparations. $\underline{J}$. Agric. Food Chem. 1993, 44, 882-886.

(10) Feussner, I.; Wasternack, C. The lipoxygenase pathway. Annu. Rev. Plant Biol. 2002, 55, 275-291.

(11) Brunton, N. P.; Cronin, D. A.; Monahan, F. J.; Durcan, R. A comparison of solid-phase microextraction (SPME) fibres for measurement of hexanal and pentanal in cooked turkey. Food Chem. 2000, 339-345.

(12) Kohlmann, M.; Bachmann, A.; Weichert, H.; Kolbe, A.; Balkenhohl, T.; Wasternack, C.; Feussner, I. Formation of lipoxygenase-pathway-derived aldehydes in barley leaves upon methyl jasmonate treatment. Eur. J. Biochem. 1999, 260, 885-895.

(13) Fauconnier, M.-L.; Rojas-Beltran, J.; Delcarte, J.; Dejaeghere, F.; Marlier, M.; du Jardin, P. Lipoxygenase pathway and membrane permeability and composition during storage of potato tubers (Solanum tuberosum L. cv. Bintjes and Désirée) in different conditions. Plant Biol. 2002, 4, 77-85.

(14) Stumpe, M.; Carsjens, J.-G.; Stenzel, I.; Göbel, C.; Lang, I.; Pawlowski, K.; Hause, B.; Feussner, I. Lipid metabolism in arbuscular mycorrhizal roots of Medicago truncatula. Phytochemistry 2005, 66, 781-791.

(15) Göbel, C.; Feussner, I.; Hamberg, M.; Rosahl, S. Oxylipin profiling in pathogen-infected potato leaves. Biochim. Biophvs. Acta 2002, 1584, 55-64.

(16) op den Camp, R. G. L.; Przybyla, D.; Ochsenbein, C.; Laloi, C.; Kim, C.; Danon, A.; Wagner, D.; Hideg, E.; Göbel, C.;
Feussner, I.; Nater, M.; Apel, K. Rapid induction of distinct stress responses after the release of singlet oxygen in Arabidopsis. Plant Cell 2003, 15, 2320-2332.

(17) Marco, A.; Navarro, J. L.; Flores, M. Volatile compounds of dry-fermented sausages as affected by solid-phase microextraction (SPME). Food Chem. 2004, 84, 633-641.

(18) Tandon, K. S.; Baldwin, E. A.; Shewfelt, R. L. Aroma perception of individual volatile compounds in fresh tomatoes (Lycopersicon esculentum, Mill.) as affected by the medium evaluation. Postharvest Biol. Technol. 2000, 20, 261-268.

(19) Petersen, M. A.; Poll, L.; Larsen, L. M. Comparison of volatiles in raw and boiled potatoes using a mild extraction technique combined with GC odour profiling and GC-MS. Food Chem. 1998, 61, 461-466.

(20) Goodridge, C. F.; Beaudry, R. M.; Pestka, J. J.; Smith, D. M. Solid-phase microextraction-gas chromatography for quantifying headspace hexanal above freeze-dried chicken myofibrils. $\underline{J}$. Agric. Food Chem. 2003, 51, 4185-4190.

(21) Galliard, T.; Phillips, D. R. Lipoxygenase from potato tubersPartial purification and properties of an enzyme that specifically oxygenates the 9-position of linoleic acid. Biochem. J. 1971, 124, $431-438$

(22) Galliard, T. Lipids of potato tubers-Lipid and fatty acid composition of tubers from different varieties of potato. $\underline{\text { J. Sci. }}$. Food Agric. 1973, 24, 617-622.

(23) Anthon, G. E.; Barrett, D. M. Thermal inactivation of lipoxygenase and hydroperoxytrienoic acid lyase in tomatoes. Food Chem. 2003, 81, 275-279.

(24) Garrote, R. L.; Sliva, E. R.; Bertone, R. A.; Roa, R. D. Predicting the end point of a blanching process. Lebensm.-Wiss. Technol. 2004, 37, 309-315.

(25) Liso, R.; De Gara, L.; Tommasi, F.; Arrigoni, O. Ascorbic acid requirement for increased peroxidase activity during potato tuber slice aging. FEBS Lett. 1985, 187, 141-145.

(26) Labuza, T. P. Kinetics of lipid oxidation in foods. CRC Crit. Rev. Food Technol. 1971, 2, 355-404.

(27) Caldelari, D.; Farmer, E. E. A rapid assay for the coupled cell free generation of oxylipins. Phvtochemistrv 1998, 47, 599604.

(28) Berger, S.; Weichert, H.; Porzel, A.; Wasternack, C.; Kühn, H.; Feussner, I. Enzymatic and nonenzymatic lipid peroxidation in leaf development. Biochim. Biophvs. Acta 2001, 1533, 266276.

(29) Arctander, S., Ed. Perfume and Flavors Chemicals; Montclair: NJ, 1969.

Received for review February 28, 2006. Revised manuscript received June 9, 2006. Accepted June 11, 2006. This work was financially supported by the Walloon Region and the European Social Fund (FIRST EUROPE “Objectif 1” Program), Belgium.

JF0605796 